\title{
Ortodontik Tedavi Sonrası Anterior Diastemaların Direkt Kompozit Rezinlerle Restorasyonu: Olgu Sunumu
}

\author{
Treatment of Anterior Diastemas With Direct Composite Resin Restorations After \\ Orthodontic Treatment: Case Report
}

\author{
Alperen Murat YALNIZ ${ }^{* 1}$ (D)
}

alp.yalniz@gmail.com

\begin{abstract}
öz
Anterior bölgede bulunan diastemalar, hastalarda estetik ve psikolojik sorunlara yol açmaktadır. Diastemaların tedavisinde ortodontik, protetik ve restoratif tedavi seçenekleri bulunmaktadır. Bazen sadece ortodontik tedavinin yeterli olmadığı durumlarda diğer tedavi yöntemleri kullanılarak diastemaların kapatılması sağlanır. Restoratif tedavi seçeneği zaman ve maliyet gibi faktörlerden daha avantajlı olduğu için protetik tedaviden daha çok tercih edilirler. Bu olgu sunumunda ortodontik tedavi sonrası çift taraflı kanin ve lateral dişler arasındaki bulunan diastemalar için restoratif tedavi gerekli olmuştur. Dişler üzerinde herhangi bir preparasyon yapılmadan \%37'lik fosforik asit (i-Gel, i-Dental, Litvanya) ile pürüzlendirilmiştir. Daha sonra tek aşamalı self etch adeziv (Clearfil S3 Bond Plus, Kuraray, Tokyo, Japonya) üretici firmanın talimatlarına göre uygulanmıștır. Tabakalama tekniği kullanılarak direkt kompozit rezin (Clearfil Majesty Esthetic, Kuraray, Tokyo, Japonya) restorasyonlar ile yapılmıștır. Son olarak ince grenli elmas frezler ve kompozit polisaj diskleri (Sof-lex, 3M ESPE, ABD) kullanılarak bitirme işlemleri uygulanmıștır. Sonuç olarak doğru bir teknik ve materyallerin titizlikle kullanımı ile direkt kompozit restorasyonlar diastemaların kapatılmasında başarılı bir tedavi yöntemidir.
\end{abstract}

Anahtar Kelimeler: Direkt kompozit restorasyon, Diastema, Polidiastema

Geliş: 14.03 .2021

Kabul: 14.04.2021

Yayın: 30.04 .2021

\begin{abstract}
Diastemas which in anterior regions of jaws, may cause aesthetic and psychological problems in patients. There are orthodontic, prosthetic and restorative treatment options in the treatment of diastemas. Sometimes, in case of only orthodontic treatment is not sufficient, other treatment methods are used to close diastemas. The restorative treatment option is usually preferred, because it is time and cost more advantageous than prosthetic treatment. In this case report, restorative treatment was required for the remaining diastemas between the bilateral canine and lateral teeth after orthodontic treatment. The teeth were roughened with 37\% phosphoric acid (i-Gel, i-Dental, Lithuania) without any preparation. Then, one-step self-etch adhesive (Clearfil S3 Bond Plus, Kuraray, Tokyo, Japan) was applied according to the manufacturer's instructions. Direct composite resin (Clearfil Majesty Esthetic, Kuraray, Tokyo, Japan) restorations were made with incremental technique. Finally, finishing process were made using fine-grain diamond burs and composite polishing discs (Sof-lex, 3M ESPE, USA). As a result, direct composite restorations are a successful treatment method for closing diastemas with a correct technique and meticulous use of materials.
\end{abstract}

Keywords: Direct composite restoration, Diastema, Polydiastema

$\begin{array}{lll}\text { Received: } 14.03 .2021 & \text { Accepted: } 14.04 .2021 & \text { Published: } 30.04 .2021\end{array}$

Atıf / Citation: Yalnız A. Ortodontik tedavi sonrası anterior diastemaların direkt kompozit rezinlerle restorasyonu: Olgu sunumu. NEU Dent J. 2021;1:45-8.

* Sorumlu Yazar / Corresponding Author

1. Özel Orka Dent Ağız ve Diş Sağlı̆̆ Polikliniği, Ankara, Türkiye

"This article is licensed under a Creative Commons Attribution-NonCommercial 4.0 International License(CC BY-NC 4.0) 


\section{GİRIŞ}

Dişlerde gelişen çürük ve diğer defektlerin iyi bir estetik sonuç sağlanarak onarılabilmesi estetik diş hekimliği ve hasta sağlı̆̆ı açısından çok önemlidir. ${ }^{1}$ Günümüzde kompozit rezin restorasyonlar estetik uygulamaların ilk aşamasıdır. Rezin esaslı kompozit materyaller, diş sert dokularından minimum kayıp ile maksimum bağlanma dayanımı, estetik ve fonksiyon kazanımı amacı ile tercih edilmektedirler. ${ }^{2}$

Kompozit rezinler, bir organik matriks ve ara bağlayıcı ajan uygulanmış inorganik doldurucu partiküllerin bir sistem içerisinde birleştirilmesinden oluşurlar ve adeziv sistemler sayesinde diş üzerine direkt olarak uygulanabilme seçeneğine sahiptirler. Adeziv sistemler "total-etch sistemler" ve "self-etch sistemler" olarak iki grupta incelenebilir. "Total-etch sistemler" üç aşamada uygulananlar ve iki aşamada uygulananlar olarak sinıflandırılırlar. "Self-etch sistemler" ise "self-etch primerler" ve "self-etch adezivler" olarak siniflandirilırlar. Self-etch adeziv sistemlerde sadece mine yüzeyine uygulanan asit (selective etch) ile adezivin minede retansiyon alanlarına yayılmasını sağlayarak mikro-mekanik bağlantı oluşturması ve bağlanmayı arttırması amaçlanır. ${ }^{3}$ Gelişen adeziv teknolojisi sayesinde dişlerin estetik görünmeyen biçim, büyüklük, form, pozisyon veya renk bozuklukları, sadece kompozit rezinler kullanılarak düzeltilebilmektedir. ${ }^{4,5}$

Anterior bölgedeki dişlerde bulunan şekil, renk, yapı ve konum bozuklukları hastalarda estetik, psikolojik ve sosyal problemlere neden olmaktadır. ${ }^{6}$ Diastemalar, aynı çene arkı üzerinde bulunan komşu iki dişin boyut farklılıklarından (konik, dar şekilli dişler gibi) ya da çene arkındaki boşluk ve diş boyutu arasındaki farklılıklardan kaynaklanan aralanmalar olarak tanımlanır. Özellikle anterior bölgede birden fazla diş arasında bulunan boşluklar, polidiastema olarak adlandırılmaktadır.

Diastemaların etiyolojisinde; diş boyut farklılıkları, şekil anomalileri ve bolton uyumsuzluğu gibi nedenler bulunmaktadır. ${ }^{7}$ Bolton uyumsuzluğu, maksiller anterior diş boyutlarının mandibular anterior diş boyutlarıyla uyumsuz olduğunda oluşmaktadır. Bolton uyumsuzluğunun analizi, her iki çene arkındaki sağ birinci molardan sol birinci molara tüm dişlerin meziodistal mesafesinin ölçülmesi ile hesaplanarak yapılmaktadır.

Bu tür estetik problemlerin üstesinden gelmek amacıyla uygulanan farklı tedavi alternatifleri mevcuttur. Bunlar; ortodontik, protetik, restoratif veya bunların kombinasyonu şeklinde yapılan tedavi seçenekleridir. Bolton uyumsuzluğuna sahip hastalarda, ortodontik tedavi seçeneği tatmin edici horizontal ve vertikal kapanıș ile proksimal kontakları tek bașına sağlayamamaktadır. Bu gibi durumlarda hem hasta hem de hekimler için daha tatmin edici bir sonuç elde etmek için ortodontik tedavi sonrasında mutlaka restoratif tedavi gereklidir. ${ }^{8}$

$\mathrm{Bu}$ çalışmanın amacı, bolton uyumsuzluğuna bağlı olarak ortodontik tedavi sonrası polidiestaması bulunan hastamıza uyguladığımız direkt kompozit rezin restorasyonların restoratif tedavi prosedürünü anlatmak ve klinik başarısını değerlendirmektir.

\section{OLGU SUNUMU}

Ortodontik tedavi sonrasında üst çene anterior bölgede polidiasteması bulunan 18 yaşında bir erkek hasta kliniğimize yönlendirildi. Yapılan klinik ve radyografik muayene sonuçlarına göre hastaya uygun tedavi seçenekleri hakkında bilgi verildi. Minimal invaziv olması, daha ekonomik olması, tek seansta uygulanabilmesi nedeniyle hastanın isteği doğrultusunda direkt kompozit rezin restorasyon tercih edildi. İşlem öncesinde hastanın başlangıç fotoğrafları çekildi (Resim 1 ve 2). Öncelikle doğal dişlere uygun renk seçimi gerçekleştirildi. Hastanın nazal yoldan nefes alma problemi olduğu için rubber-dam izolasyonu sağlanamadı. Dişlerin diastemaya bakan yüzeyleri \%37'lik fosforik asit (i-Gel, i-Dental, Litvanya) uygulandı ve tek aşamalı self etch adeziv (Clearfil S3 Bond Plus, Kuraray, Tokyo, Japonya) üretici firmanın talimatlarına göre uygulandı. Daha sonra uygun diş şekil ve formları şeffaf bantlar yardımıyla verilerek tabakalama tekniği kullanılarak direkt kompozit rezin (Clearfil Majesty Esthetic, Kuraray, Tokyo, Japonya) restorasyon yapıldı. Son olarak ince grenli elmas frezler ve kompozit polisaj diskleri (Sof-lex, 3M ESPE, ABD) kullanılarak bitirme ișlemleri uygulandı ve tedavi sonrası bitiş fotoğrafları çekildi (Resim 3 ve 4).

Resim 1: Hastanın sağ taraf başlangıç fotoğrafı

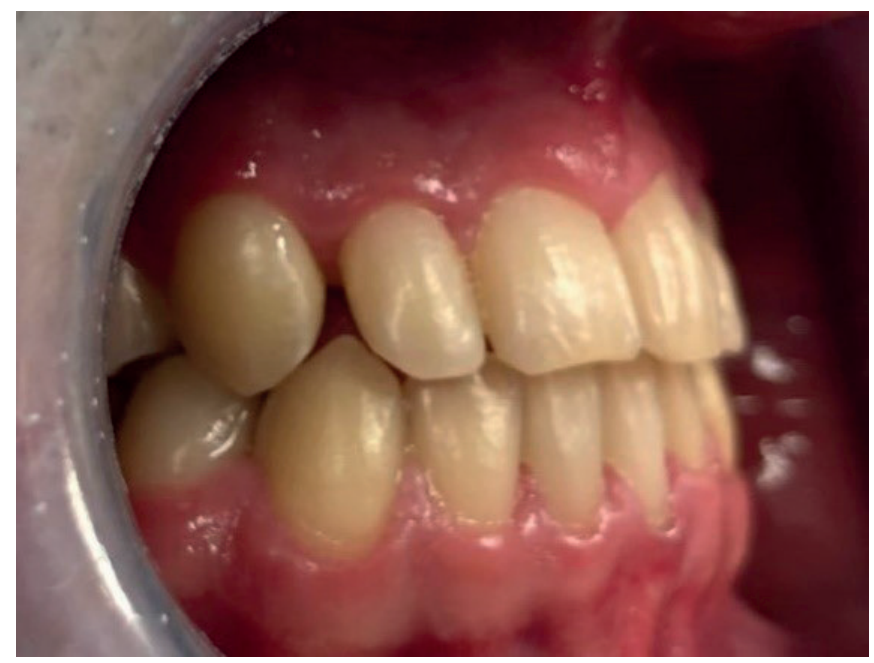


Resim 2: Hastanın sol taraf başlangıç fotoğrafı

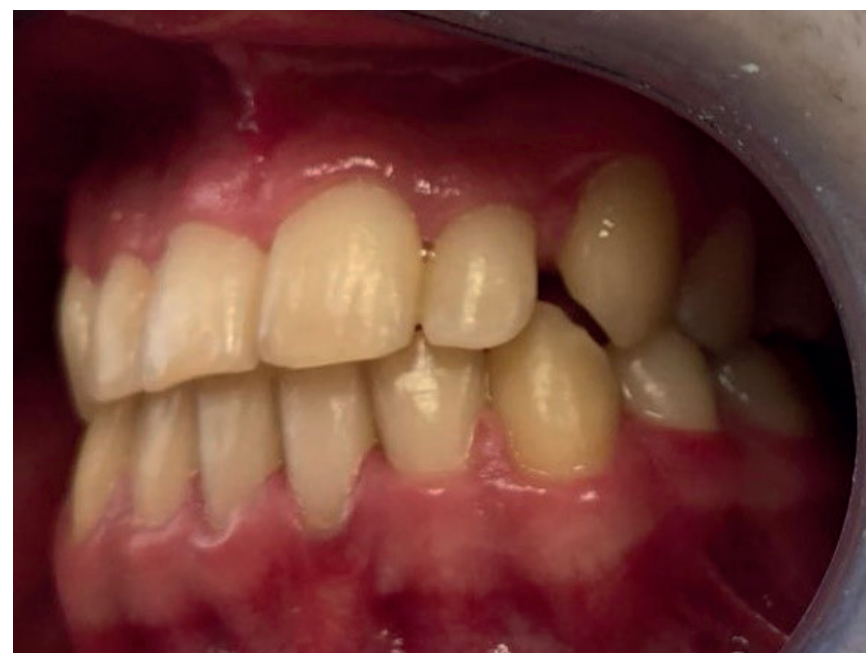

Resim 3: Hastanın sağ taraf bitim fotoğrafı

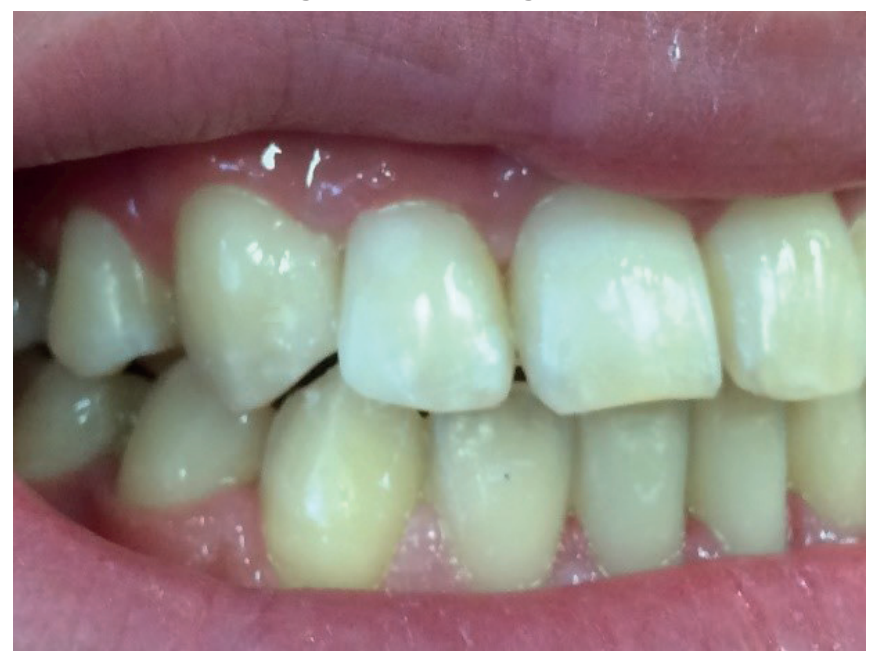

Resim 4: Hastanın sol taraf bitim fotoğrafı

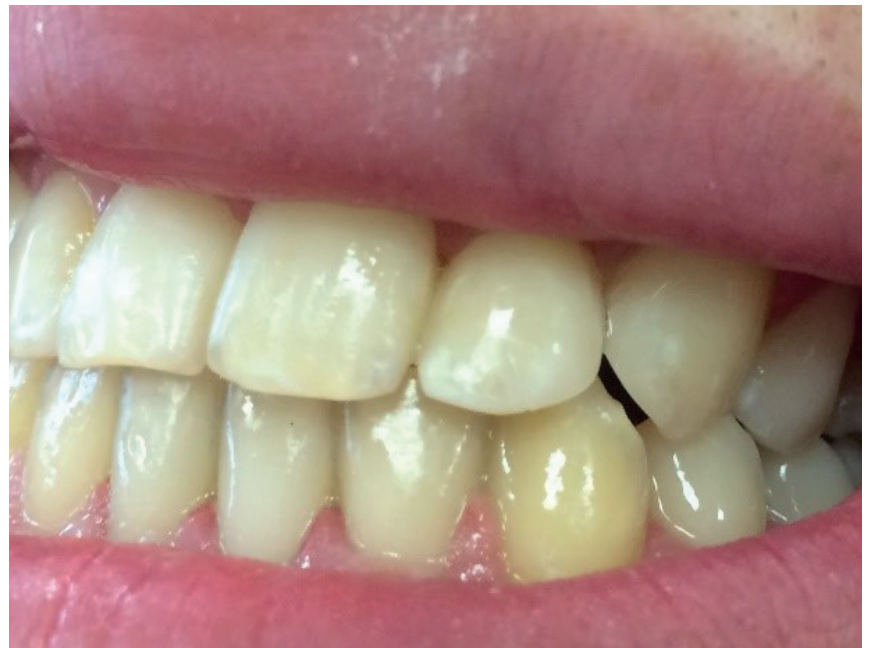

\section{TARTIŞMA}

Özellikle anterior dişler arasında bulunan boşluklar( diastemalar) hastalarda estetik kaygılara yol açmaktadır. Diastemaların tedavisinde; indirekt veya direkt teknikler arasında seçim yaparken hastanın yaşı, diastemanın dişler arası mesafesi, zaman ve maliyet gibi kriterler göz önüne alınmalıdır.

Kompozit rezinler ile yapılan direkt restorasyonlar maliyet açısından indirekt tekniklere göre uygundur ve laboratuvar işlemleri gerektirmezler. Genellikle minimal invaziv restorasyonlardır. Oluşabilecek kırıkların tamir edilebilmesi alternatiflerine göre daha kolaydır. Ayrıca; uygulamanın tek seansta bitirilebilmesi zaman açısından hekim ve hasta için daha avantajlıdır. ${ }^{9}$ Kompozit rezinlerin; polimerizasyon büzülmesi, mikrosızıntı, düşük aşınma ve kırılma direnci dezavantajları da bulunmaktadır. ${ }^{10}$ Tedavi sırasında kompozit rezin materyalinin kan, tükürük ya da dișeti cebinden gelen sıvilar ile kontaminasyonu restorasyonun başarısını olumsuz yönde etkilemektedir. Polimerizasyon işlemleri ağız içerisinde olmayan indirekt kompozit rezinler veya diğer seramik ya da porselen esaslı restorasyonların oral kavite sıvilarından daha az etkilenerek daha iyi renk stabilitesi sağladığı gösterilmiştir. ${ }^{11}$ Sunulan olgudaki hastaya tedavi seçeneklerinin avantaj ve dezavantajları anlatılmıştır ve kompozit rezin ile direkt restorasyon yapılmasına karar verilmiştir.

Kompozit rezinlerin polimerizasyon sırasinda meydana gelen büzülmelerinin azaltılması için çalışmalar yapılmaktadır. Kompozit rezinler için yeterli polimerizasyon restorasyonun başarısı için çok önemlidir. Kompozit rezinlerin yetersiz polimerizasyonuna bağlı olarak su emilimi gerçekleşir. Su emilimi özellikle anterior bölgede yapılan restorasyonlarda estetik problemlere yol açabilir. ${ }^{12}$ Bu sebeple sunulan olguda kullanılan adeziv materyal ve kompozit rezin üretici firma önerileri doğrultusunda polimerize edilmiştir.

Kompozit rezinler ile yapılan restorasyonların son aşaması olan bitirme ve cila işlemleri çok önemlidir. Restorasyonun uzun vadede başarılı olması için pürüzsüz bir yüzey oluşturulmalıdır. ${ }^{13}$ Ağız içerisindeki pürüzlü yüzeylerde bakterilerin birikimi daha çabuk ve kolay olmaktadır. Bu birikim zaman içerisinde sekonder çürüklere neden olabilir. Restorasyona daha estetik görünüm kazandırmak ve bakteri birikimini azaltmak için bitirme ve cila işlemleri özenle yapılmalıdır. ${ }^{13}$ Günümüzde farklı marka, yapı ve renklerde bir çok kompozit bulunmaktadır. Bu vakada nanohibrit bir kompozit olan Clearfil Majesty Esthetic (Kuraray, Tokyo, Japonya) kullanılmış ve uygun diskler ile cila işlemleri yapılmıştır. 
Diastemaların geniș olduğu durumlarda karșılașılan problemlerden en önemlisi; restorasyon sonrasında kontak noktası ile dișeti arasında kalan oral kavitenin boșluğunu yansıtan siyah üçgen alanlardır. Oluşan siyah üçgen alanları dișetinin doldurup dolduramayacağını belirlemede dişlerin kontak noktasının alveolar kemik kretine olan mesafesine bakılmalıdır. İki nokta arasındaki mesafe 5 milimetre veya altında olduğunda, genellikle interdental papilin oluștuğu ve siyah üçgen alanların dolduğu gösterilmiştir. ${ }^{14} \mathrm{Me}$ safe 5 milimetreden daha fazla olduğunda kompozit rezinler ile yapılan direkt restorasyonlarla dişlere yeniden form ve şekil kazandırmak estetik problemi bir miktar çözebilir ancak dișetini șekillendirmede yetersiz kalabilir. Bu yüzden diastemaların restorasyonu yapılırken oluşabilecek siyah üçgen alanların engellenmesi için interdental papil ve olușturulacak kontak noktalarının konumu dikkatle değerlendirilmelidir. $^{9,15}$

\section{SONUC}

Gelișen adeziv ve kompozit teknolojisi ile direkt kompozit rezin restorasyonlar non-invaziv ya da minimal invaziv olarak önemli klinik tedavi alternatiflerinden biri olduğunu göstermiştir. Direkt kompozit restorasyonlar uygun endikasyon ile ideal şartlarda uygulandıklarında, anterior bölgedeki dişlerin estetik amaçlı tedavilerinde rahatlıkla kullanılırlar. Tedavide kullanılan materyallerin yapı ve renginin uzun vadede değișebileceği ve tekrar cila ișlemi gerekebileceği hastaya bildirilmelidir. Ayrıca, hastaların oral hijyen motivasyonu sağlanarak, diș fırçalama ve diş ipi kullanma alıșkanlığı kesinlikle hatırlatılmalıdır.

\section{KAYNAKLAR}

1. Dayangaç GB. Kompozit Rezin Restorasyonlar. 2.Baskl. İstanbul: Quintessence Yayıncllı; 2011. p1.

2. Baratieri LN, Monteiro Júnior S, Correa M, Ritter AV. Posterior resin composite restorations: a new technique. Quintessence Int. 1996 Nov;27(11):733-8.

3. Frankenberger R, Lohbauer U, Roggendorf MJ, Naumann M, Taschner M. Selective enamel etching reconsidered: better than etch-and-rinse and self-etch? J
Adhes Dent. 2008 Oct;10(5):339-44.

4. de Araujo Júnior EM, Baratieri LN, Monteiro Júnior S, Vieira LC, de Andrada MA. Direct adhesive restoration of anterior teeth. Part 1. Fundamentals of excellence. Pract Proced Aesthet Dent. 2003 Apr;15(3):233-40.

5. de Araujo EM Jr, Baratieri LN, Monteiro S Jr, Vieira LC, de Andrada MA. Direct adhesive restoration of anterior teeth: Part 2. Clinical protocol. Pract Proced Aesthet Dent. 2003 Jun;15(5):351-7.

6. Chu FC, Siu AS, Newsome PR, Wei SH. Management of median diastema. Gen Dent. 2001 MayJun;49(3):282-7.

7. Oesterle LJ, Shellhart WC. Maxillary midline diastemas: a look at the causes. J Am Dent Assoc. 1999 Jan;130(1):85-94.

8. Furuse AY, Herkrath FJ, Franco EJ, Benetti AR, Mondelli J. Multidisciplinary management of anterior diastemata: clinical procedures. Pract Proced Aesthet Dent. 2007 Apr;19(3):185-9.

9. Wolff D, Kraus T, Schach C, Pritsch M, Mente J, Staehle $\mathrm{HJ}$, Ding P. Recontouring teeth and closing diastemas with direct composite buildups: a clinical evaluation of survival and quality parameters. J Dent. 2010 Dec;38(12):1001-9.

10. Stappert CFJ, Ozden U, Gerds T, Strub JR. Longevity and failure load of ceramic veneers with different preparation designs after exposure to masticatory simulation. Journal of Prosthetic Dentistry. 2005 Aug;94(2):132-139.

11. Walls AW, Steele JG, Wassell RW. Crowns and other extra-coronal restorations: porcelain laminate veneers. Br Dent J. 2002 Jul 27;193(2):73-6.

12. Civelek A, Özel E. Işılkla polimerize olan kompozitlerin polimerizasyon derinliği. Akademik Dental Diş Hekimliği Dergisi. 2004;6(4):34-8.

13. Venturini D, Cenci MS, Demarco FF, Camacho GB, Powers JM. Effect of polishing techniques and time on surface roughness, hardness and microleakage of resin composite restorations. Oper Dent. 2006 JanFeb;31(1):11-7.

14. Cho HS, Jang HS, Kim DK, Park JC, Kim HJ, Choi SH, Kim CK, Kim BO. The effects of interproximal distance between roots on the existence of interdental papillae according to the distance from the contact point to the alveolar crest. J Periodontol. 2006 Oct;77(10):1651-7.

15. De Araujo EM Jr, Fortkamp S, Baratieri LN. Closure of diastema and gingival recontouring using direct adhesive restorations: a case report. J Esthet Restor Dent. 2009;21(4):229-40. 